\title{
Sulfonated Polyether Ether Ketone-Based Composite Membranes Doped with a Tungsten-Based Inorganic Proton Conductor for Fuel Cell Applications
}

\author{
Barbara Mecheri, ${ }^{\text {a,b,z }}$ Alessandra D'Epifanio, ${ }^{a}$ M. Luisa Di Vona, ${ }^{a}$ \\ Enrico Traversa, ${ }^{a} *$ Silvia Licoccia, ${ }^{a}, *$ and Masaru Miyayama ${ }^{\mathrm{b}}$ \\ ${ }^{a}$ Dipartimento di Scienze e Tecnologie Chimiche, Università di Roma "Tor Vergata," 00133 Roma, Italy \\ ${ }^{b}$ Research Center for Advanced Science and Technology, The University of Tokyo, Meguro-ku, \\ Tokyo 153-8904, Japan
}

Sulfonated polyether ether ketone (SPEEK)-based composite membranes doped with hydrated tungsten oxide were prepared and studied for proton exchange membrane applications. Hydrated tungsten oxide $\left(\mathrm{WO}_{3} \cdot 2 \mathrm{H}_{2} \mathrm{O}\right)$ was synthesized via acidic hydrolysis of sodium tungstate and its structure and physicochemical features were investigated by thermogravimetric analysis (TG), X-ray diffraction (XRD), and electrochemical impedance spectroscopy (EIS). SPEEK/ $\mathrm{WO}_{3} \cdot 2 \mathrm{H}_{2} \mathrm{O}$ composite membranes were prepared by mixing proper amounts of SPEEK and hydrated $\mathrm{WO}_{3}$ in dimethylacetamide as casting solvent. The composite membranes were characterized by XRD, TG-DTA, EIS, and water uptake measurements as a function of the oxide content in the membrane. In particular, XRD patterns as well as TG measurements indicated the existence of a coordinative interaction between the water molecules of tungsten oxide and the SPEEK sulfonic acid groups. This interaction lead to the enhancement of the membrane proton conductivity, as well as of their properties, from the point of view of heat resistance and water solubility. In fact, the addition of tungsten oxide resulted in higher proton conductivity, improved heat resistance, and lower water solubility. (C) 2006 The Electrochemical Society. [DOI: 10.1149/1.2158571] All rights reserved.

Manuscript submitted August 3, 2005; revised manuscript received October 28, 2005. Available electronically January $19,2006$.

During the past two decades, significant worldwide efforts have been devoted to develop fuel cell materials and systems for electrochemical energy conversion. Among various types of fuel cells, the proton exchange membrane fuel cell (PEMFC) is one of the most promising candidates for portable technologies and electric vehicles. For these applications, it is important to develop new membranes capable of operating at intermediate temperatures $\left(90-130^{\circ} \mathrm{C}\right)$ to enhance fuel oxidation kinetics and reduce heat exchange requirements. ${ }^{1}$

Several methods have been proposed to increase the performance of PEMs and promising results have been obtained with the use of composite membranes, where inorganic particles are embedded in a conducting polymer matrix. ${ }^{2-6}$

In the present work a similar approach was followed and the polymer chosen for the fabrication of proton conductive membranes was sulfonated polyetheretherketone (SPEEK). Polyetheretherketone (PEEK) is a semicrystalline thermoplastic polymer known for its good thermal stability and excellent mechanical properties. As for most sulfonated arylene main chain polymers, its conductivity strongly depends on the degree of sulfonation ( $\mathrm{DS}=$ number of $-\mathrm{SO}_{3} \mathrm{H}$ groups per repeat unit): at reduced levels of sulfonation the hydrophilicity of aromatic polymers is too low to reach the water content needed to ensure values of proton conductivity acceptable for use in fuel cells. ${ }^{7}$ Conversely, at high sulfonation degrees, the mechanical properties of the membrane deteriorate. ${ }^{3}$ This drawback can be overcome producing hybrid organic-inorganic membranes with controlled mechanical, physical, and chemical properties. ${ }^{8}$

Among several general approaches to increase proton transport as well as the mechanical properties through the use of hybrid membranes, in this work our strategy was to use a proton conductive filler. The filler was introduced with the aim of reducing both the membrane permeability to methanol and the conduction losses at low humidity contents. ${ }^{9}$ For these reasons, the incorporation of a hydrophilic oxide into a SPEEK matrix was carried out.

Among inorganic proton conductors, di-hydrated tungsten oxide $\left(\mathrm{WO}_{3} \cdot 2 \mathrm{H}_{2} \mathrm{O}\right)$ exhibits relatively high proton conductivity up to $150^{\circ} \mathrm{C} .{ }^{10}$ This compound crystallizes in a layered structure, analogous to that of $\mathrm{MoO}_{3} \cdot 2 \mathrm{H}_{2} \mathrm{O}$, in which infinite layers of cornershared deformed $\mathrm{MoO}_{5}\left(\mathrm{H}_{2} \mathrm{O}\right)$ octahedra are stacked above each

\footnotetext{
* Electrochemical Society Active Member.

z E-mail: barbara.mecheri@uniroma2.it
}

other with interlayered water molecules connected by hydrogen bonding between the two kinds of water molecules. ${ }^{11}$ This ceramic material cannot be easily shaped in the form of a membrane, a problem that might be solved with the formation of a composite system where an organic polymer may supply the needed plastic properties for fuel cell applications.

SPEEK/ $/ \mathrm{WO}_{3} \cdot 2 \mathrm{H}_{2} \mathrm{O}$ composite membranes were prepared by mixing proper amounts of SPEEK and hydrated $\mathrm{WO}_{3}$ in $\mathrm{N}, \mathrm{N}$-dimethylacetamide (DMA); the structural and electrochemical performance of the resulting membranes was evaluated.

\section{Experimental}

Materials.- PEEK was obtained by VICTREX in the form of extrudate (Mw: 38,300 g/mol, 132 repeat units per mole). SPEEK was obtained in concentrated sulfuric acid $\left(\mathrm{H}_{2} \mathrm{SO}_{4} 96 \%\right.$, Aldrich) according to published procedure. ${ }^{7}$ The DS was determined by titration and by ${ }^{1} \mathrm{H}$ NMR, resulting to be 0.8 . DMA $(98 \%)$ was obtained by Wako. Hydrated tungsten oxide $\left(\mathrm{WO}_{3} \cdot 2 \mathrm{H}_{2} \mathrm{O}\right)$ was synthesized as previously reported. ${ }^{11,12} 50 \mathrm{~mL}$ of a $1 \mathrm{M}$ (saturated) sodium tungstate(VI) dihydrate $\left(\mathrm{Na}_{2} \mathrm{WO}_{4} \cdot 2 \mathrm{H}_{2} \mathrm{O} 99 \%\right.$, Wako) solution in water were added dropwise into $450 \mathrm{~mL}$ of $3 \mathrm{M} \mathrm{HCl}$ solution at $5^{\circ} \mathrm{C}$. A white precipitate appeared immediately and it turned yellow in $30 \mathrm{~min}$. The precipitate was filtered and washed with $250 \mathrm{~mL}$ of $0.1 \mathrm{M} \mathrm{HCl}$. The solid was then rinsed several times with water until no chloride ions were detectable. The yellow powder thus obtained was dried in a desiccator.

Membrane preparation.-Composite membranes were prepared at two different oxide contents, i.e., 23 and $50 \mathrm{wt} \%$. SPEEK $(0.4 \mathrm{~g})$ was dissolved in DMA $(15 \mathrm{~mL})$ at $40^{\circ} \mathrm{C}$ under stirring. After complete dissolution of the polymer, the proper amount of hydrated tungsten oxide was added. The yellow suspension was kept stirring for $5 \mathrm{~min}$, treated in an ultrasonic bath for $5 \mathrm{~min}$, then kept stirring at $40^{\circ} \mathrm{C}$ for $2 \mathrm{~h}$, and finally cast on a Teflon plate. The Teflon plate was kept at $40^{\circ} \mathrm{C}$ overnight. Membranes were peeled off and dried in a desiccator at room temperature. The thickness of the membrane falls in the range $140-240 \mu \mathrm{m}$.

Reference pure SPEEK membranes were prepared following the same procedure.

Methods.- X-ray diffraction (XRD) patterns were recorded at room temperature by means of a PW 1729 X-ray generator (Philips 
International, Inc.) using $\mathrm{Cu} \mathrm{K} \alpha$ radiation. Data were collected by the step-scanning mode with steps of $0.05^{\circ}$ (time per step: $1 \mathrm{~s}$ ).

Thermal analysis was performed by using a Thermoplus TG 8120 apparatus (Rigaku, Japan) in dry air with a heating rate of $2{ }^{\circ} \mathrm{C} / \mathrm{min}$.

Water uptake (W.U.) was calculated as reported in the literature ${ }^{7}$ using the following equation

$$
\text { W.U. }(\%)=\left[\left(W_{\text {wet }} / W_{\text {dry }}\right)-1\right] \times 100
$$

where W.U. is expressed in percentage units, $W_{\text {wet }}$ is the weight of the wet membrane, and $W_{\text {dry }}$ is the weight of the dry membrane.

The dry membranes were immersed in $20 \mathrm{~mL}$ of water and kept in water for different times (from 15 to $145 \mathrm{~min}$ ) at room temperature, then dried with absorbent paper, and weighted.

Conductivity measurements on powders were performed using pellets ( $4 \mathrm{~mm}$ diameter and $1 \mathrm{~mm}$ thickness) of hydrated tungsten oxide formed by a cold pressing technique at a pressure of $230 \mathrm{MPa}$. Carbon (acetylene black) electrodes were attached on both sides of the pellet simultaneously when it was pressed. The pellet was inserted between Pt-current collectors using a spring setup. Conductivity measurements on membranes were performed inserting them between Pt-current collectors using the same setup. A silver paste (Ag dispersion in ethanol) was used for improving the contact between $\mathrm{Pt}$ and the membranes. The sample holder containing the membrane was dried at $40^{\circ} \mathrm{C}$ for $2 \mathrm{~h}$ to dry the silver paste before impedance measurements. The conductivity was determined by electrochemical impedance spectroscopy (EIS) measurements using a Hewlett Packard 4192A impedance analyzer at the oscillation amplitude of $0.1 \mathrm{~V}$ in the frequency range of $5 \mathrm{~Hz}$ to $5 \mathrm{MHz}$. The water vapor pressure was controlled using a thermostatic compartment in which water-saturated air was introduced. The sample temperature was monitored using a thermocouple placed near the sample pellet. The resistance of the tungsten oxide pellets was obtained from the intersection of the semicircle on the real axis. The resistance of the membranes, and hence, their conductivity, was calculated by a linear fit of the impedance spectra in their linear portion. From the resistance values we obtained the conductivity $(\sigma)$ value using the following equation

$$
\sigma=(d / R A)
$$

where $R$ is the resistance, $d$ is the distance between electrodes, and $A$ is the electrode area.

EIS and water uptake measurements were performed before and after the activation of the membranes with sulfuric acid. The activation procedure was carried out as follows: The membranes were immersed in $5 \mathrm{M} \mathrm{H}_{2} \mathrm{SO}_{4}$ for $1 \mathrm{~h}$ at room temperature, then rinsed with water. The membranes were dried in a desiccator for 2 days and disks of 8-mm diam were cut from the membranes and weighed. The disks were then soaked in water at room temperature and weighed after blotting with absorbent paper.

\section{Results and Discussion}

Characterization of $\mathrm{WO}_{3} \cdot 2 \mathrm{H}_{2} \mathrm{O}$.- - Figure 1 shows the XRD pattern of $\mathrm{WO}_{3} \cdot 2 \mathrm{H}_{2} \mathrm{O}$ powder (pattern a); patterns (b) and (c) are explained later. The pattern is in good agreement with previous literature reports on the structural data of dihydrated tungsten oxide. ${ }^{11}$ The compound is characterized by a layered structure in which each $\mathrm{W}$ atom has one terminal oxygen, one coordinated water, and four bridging oxygen atoms with which $\mathrm{WO}_{5}\left(\mathrm{H}_{2} \mathrm{O}\right)$ octahedra are connected with each other to form a neutral $\mathrm{WO}_{3}\left[\mathrm{H}_{2} \mathrm{O}\right]$ layer. The second water molecule, not bound to $\mathrm{W}$, lies between such layers as interlayer crystal water.

Figure 2 shows the thermogravimetric (TG) curve of $\mathrm{WO}_{3} \cdot 2 \mathrm{H}_{2} \mathrm{O}$ powder, which confirmed the existence of two differently bound water molecules. Two distinct weight losses were, in fact, observed, each one corresponding to the loss of one water molecule. According to previous work, the first weight loss step, at about $70^{\circ} \mathrm{C}$, was

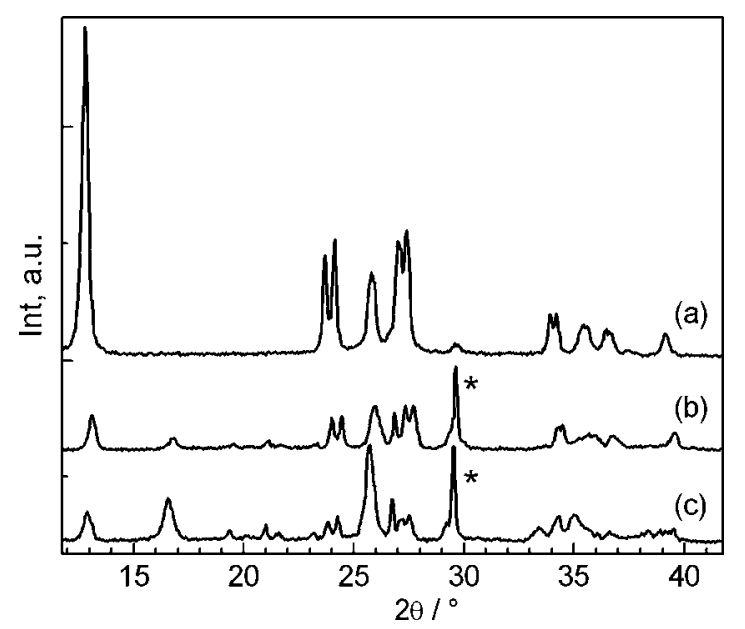

Figure 1. XRD patterns of $\mathrm{WO}_{3} \cdot 2 \mathrm{H}_{2} \mathrm{O}$ powder (a), SPEEK/WO $\mathrm{W}_{3} \cdot 2 \mathrm{H}_{2} \mathrm{O}$ (23 wt \%) membrane (b), and SPEEK/ $\mathrm{WO}_{3} \cdot 2 \mathrm{H}_{2} \mathrm{O}(50$ wt \%) membrane (c). The asterisk refers to a sample holder peak.

attributed to the loss of interlayer water and the second one, at higher temperatures, to the loss of coordinated water. ${ }^{11}$

The proton conductivity of the $\mathrm{WO}_{3} \cdot 2 \mathrm{H}_{2} \mathrm{O}$ pellet at different temperatures and at saturated water vapor pressure was evaluated.

Figure 3 shows the Arrhenius plot for the dihydrated tungsten oxide pellet. Conductivity increased with temperature, showing two different linear trends above and below $60^{\circ} \mathrm{C}$. The activation energies (calculated independently in the low- and high-temperature regions) were 0.13 and $0.31 \mathrm{eV}$, respectively. ${ }^{11}$ The two different energy activation values are indicative of two different proton conduction mechanisms. At low temperatures, in fact, the low activation energy value suggests a surface mechanism with protons migrating through surface-adsorbed water. ${ }^{13}$ At higher temperatures a bulk mechanism occurred in which conduction takes place through the hydrogen bond network formed by the interlayer and coordinated water molecules. ${ }^{11}$

Characterization of SPEEK.- The proton conductivity of SPEEK membranes was evaluated using EIS measurements. Figure 4 shows the comparison between the complex impedance plots of as-prepared and activated SPEEK membranes at $100 \%$ relative humidity (RH) at room temperature. The coordination of SPEEK sulfonic groups with the solvent used for casting is known to induce a decrease in proton conductivity. ${ }^{14,15}$ Activation of the membranes with sulfuric acid allows breakup of the acid-base interaction be-

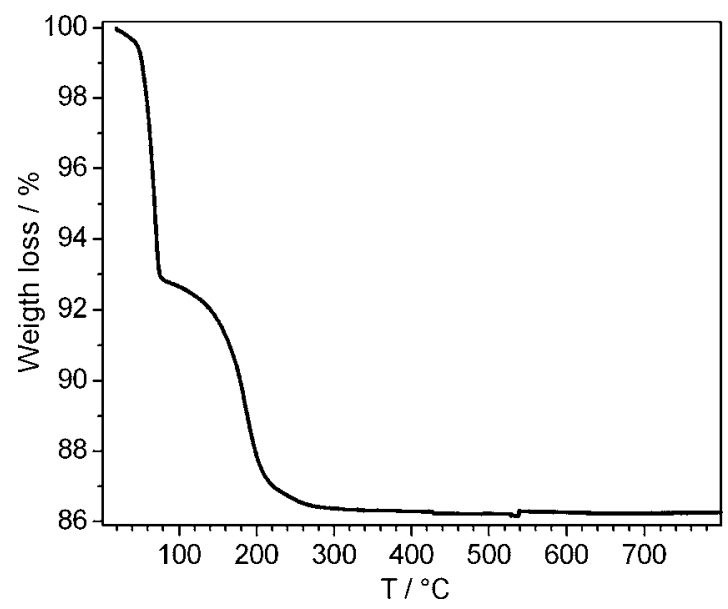

Figure 2. TG curve of $\mathrm{WO}_{3} \cdot 2 \mathrm{H}_{2} \mathrm{O}$ powder. 


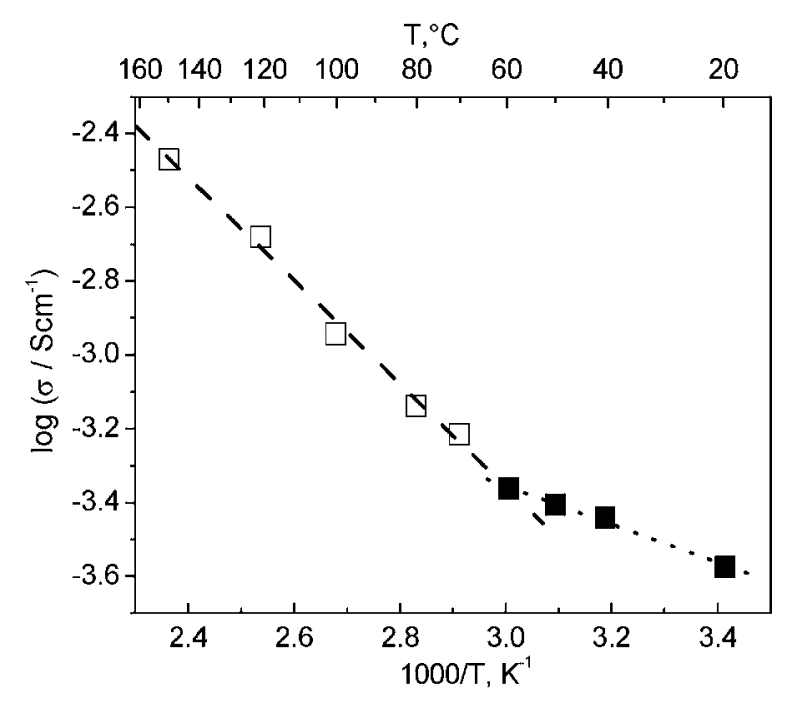

Figure 3. Arrhenius plot of $\mathrm{WO}_{3} \cdot 2 \mathrm{H}_{2} \mathrm{O}$ pellet at $100 \% \mathrm{RH}$. The fitting was done using the data above $60^{\circ} \mathrm{C}$ (empty symbols) and below $60^{\circ} \mathrm{C}$ (filled symbols) separately.

tween SPEEK and DMA, without heating the membrane at high temperature, which would induce water loss from the hydrated tungsten oxide to be used as filler. The EIS measurements confirmed that the activation procedure was successful; in fact, the high-frequency semicircle observed for the as-prepared membrane disappeared upon activation (see inset in Fig. 4), demonstrating the removal of the polymer/solvent acid-base interactions that are known to produce discontinuities hindering the migration of $\mathrm{H}^{+}$ions. ${ }^{16}$

Figure 5 shows the Arrhenius plots, obtained from EIS measurements, of as-prepared and activated SPEEK membranes. At temperatures above $50^{\circ} \mathrm{C}$ and at $100 \% \mathrm{RH}$, partial dissolution of the polymer in water was observed. However, in the temperature range investigated, conductivity increased with temperature for both asprepared and activated membranes, and almost the same conductivity value was reached at $50^{\circ} \mathrm{C}$ when the interaction with the casting solvent is substituted by that with water. It is interesting to point out that the activation energy was higher for the as-prepared membrane

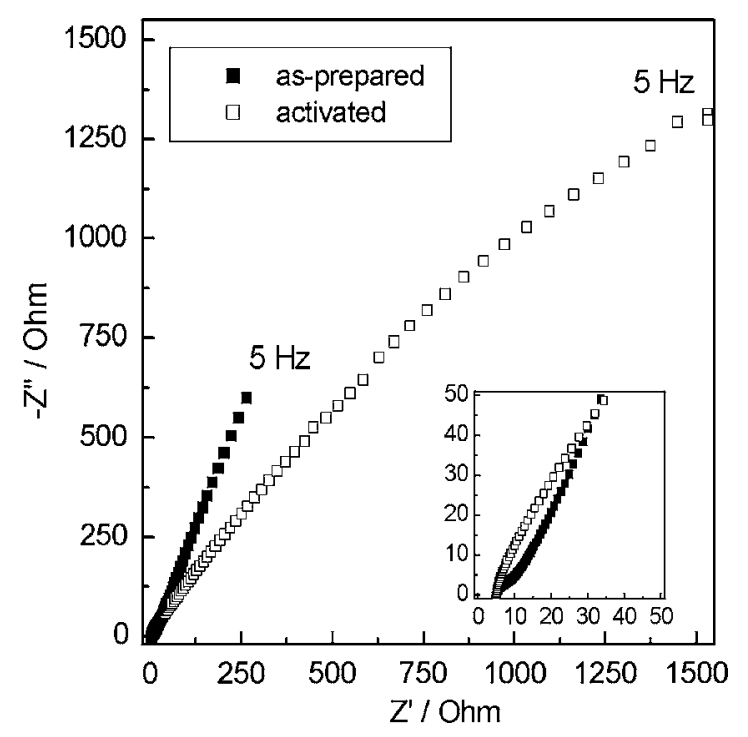

Figure 4. Typical complex impedance plane plot for pure SPEEK membranes measured at $100 \% \mathrm{RH}$ and at room temperature. A high-frequency zoom of this plot is reported in the inset.

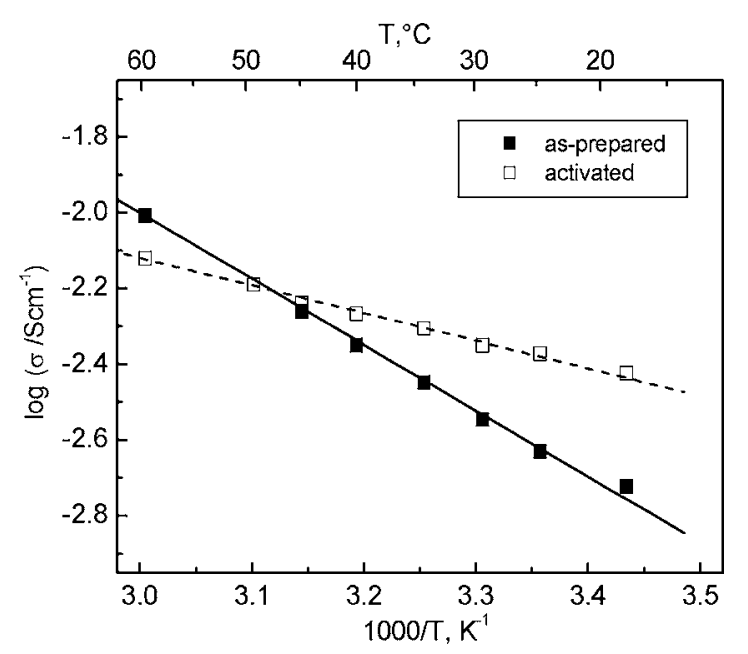

Figure 5. Arrhenius plot for as-prepared and activated pure SPEEK membranes at $100 \% \mathrm{RH}$.

$(0.37 \mathrm{eV})$ than for the activated one $(0.17 \mathrm{eV})$, in agreement with previous literature reports on the variation of activation energy with the membrane water content. ${ }^{17}$ Eikerling and Kornyshev found that in a dry membrane, which contains only residual water molecules that are strongly bound to the pore surfaces, the activation energy is in the range $0.4-0.5 \mathrm{eV}$. In the highly swollen membrane, the activation energy is $0.1 \mathrm{eV}$, which is close to the bulk water value. At intermediate degrees of wetting, the activation energy varies between these two values, allowing the conclusion that in a swollen membrane the influence of interfaces and fixed groups is probably negligible and only the bulk water degrees of freedom contribute to the proton transfer, while in narrow pores, the surface mechanisms of conductivity are dominant.

Characterization of SPEEK/ $/ \mathrm{WO}_{3} \cdot 2 \mathrm{H}_{2} \mathrm{O}$ composite membranes.-Composite membranes SPEEK/ $/ \mathrm{WO}_{3} \cdot 2 \mathrm{H}_{2} \mathrm{O}$ at two different oxide contents, i.e., 23 and $50 \mathrm{wt} \%$, were prepared. Figure 1 shows the comparison between the XRD pattern of $\mathrm{WO}_{3} \cdot 2 \mathrm{H}_{2} \mathrm{O}$ powder (Fig. 1a) and the SPEEK/ $/ \mathrm{WO}_{3} \cdot 2 \mathrm{H}_{2} \mathrm{O}$ composite membranes (Fig. $1 \mathrm{~b}$ and c); the XRD pattern of a pure SPEEK membrane (not shown) is typical of an amorphous structure. The peaks due to tungsten oxide could clearly be identified in the XRD patterns of the composite membranes, although with some differences with respect to the pattern of the pure oxide. Such differences can be ascribed to a structural modification of the oxide occurring upon membrane formation. In fact, patterns (b) and (c) showed a new peak at $2 \vartheta$ $=17^{\circ}$ due to the monohydrate phase ${ }^{11}$ that was absent in pattern (a). This finding indicates that the hydration grade of the oxide in the membrane changed with respect to the precursor powder and, in particular, it decreased with increasing oxide content in the membrane because of coordination of the oxide interlayer water molecules with the sulfonic acid groups of the polymer.

Such coordinative interaction resulted also from the TG analysis carried out on the membranes. Figure 6 shows the TG curves of the three tested SPEEK-based membranes. After two weight losses due to evaporation of residual water and DMA, which ended at about $260^{\circ} \mathrm{C}$, a third step was observed. This step can be attributed to the splitting-off of sulfonic acid groups. ${ }^{7}$ It is interesting to observe that the temperature at which the splitting-off of the $\mathrm{SO}_{3} \mathrm{H}$ groups of SPEEK $\left(T_{\mathrm{S}}\right)$ occurred varied with inorganic filler content, as shown in the inset in Fig. 6. The presence of the filler induced an increase in $T_{\mathrm{S}}$, thereby supporting the hypothesis of a coordinative interaction between interlayer water molecules of the oxide and $\mathrm{SO}_{3} \mathrm{H}$ groups of SPEEK. The fourth step in the TG curves, ending at $525^{\circ} \mathrm{C}$, is due to polymer pyrolysis. 


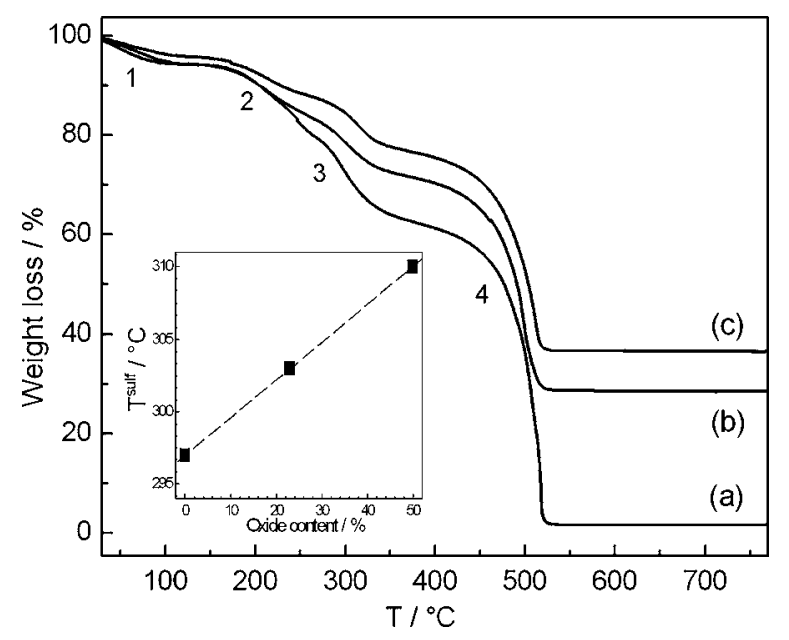

Figure 6. TG curves of pure SPEEK membrane (a), SPEEK/ $\mathrm{WO}_{3} \cdot 2 \mathrm{H}_{2} \mathrm{O}$ (23 wt \%) membrane (b), and SPEEK/ $\mathrm{WO}_{3} \cdot 2 \mathrm{H}_{2} \mathrm{O}(50 \mathrm{wt} \%)$ membrane (c). (Inset) The temperature at which the splitting-off of the $-\mathrm{SO}_{3} \mathrm{H}$ of SPEEK $\left(T_{S}\right)$ occurred $v s$ the oxide content in the membrane.

Figure 7 shows the comparison of the complex impedance plots for the as-prepared and activated SPEEK/ $/ \mathrm{WO}_{3} \cdot 2 \mathrm{H}_{2} \mathrm{O} 23 \mathrm{wt} \%$ membranes at room temperature and at $100 \% \mathrm{RH}$. The highfrequency resistance was much lower than that observed for the reference SPEEK membranes (Fig. 4), demonstrating that the activation procedure did not significantly affect the conductivity of composite membranes. Both the as-prepared and activated composite membranes showed in fact similar $\sigma$ values, at variance with what observed for pure SPEEK. The same behavior was observed for the composite membrane containing $50 \mathrm{wt} \%$ filler. These observations indicate that the water molecules of tungsten oxide are coordinated by the $\mathrm{SO}_{3} \mathrm{H}$ groups of SPEEK, resulting in removal of residual DMA and, therefore, in electrical discontinuities of the membrane.

Figure 8 shows the Arrhenius plots of the composite membranes compared with the as-prepared SPEEK reference membrane. The proton conductivity of the composite membranes was higher in the whole range of temperatures, and at variance with what was ob-

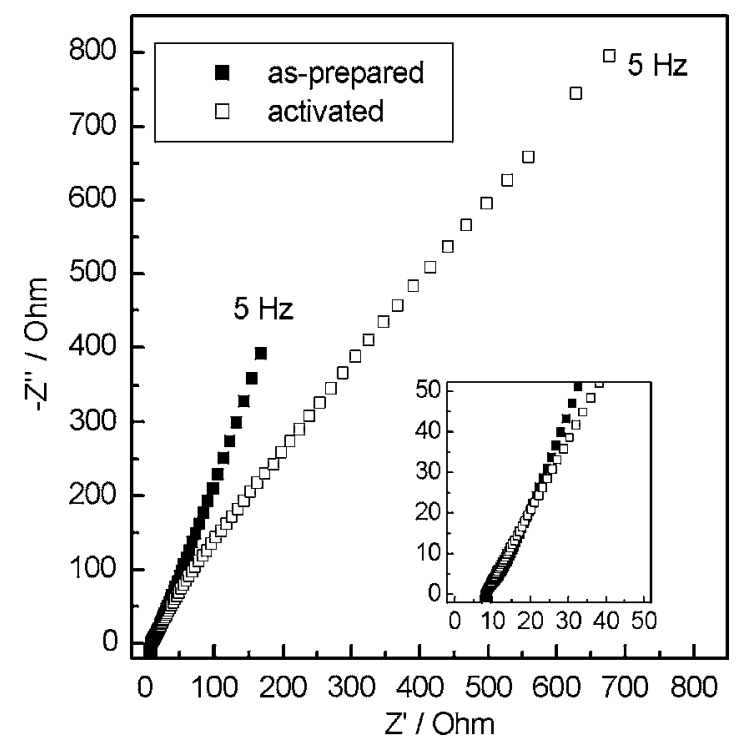

Figure 7. Typical complex impedance plane plot for SPEEK/ $/ \mathrm{WO}_{3} \cdot 2 \mathrm{H}_{2} \mathrm{O}$ (23 wt \%) membrane measured at $100 \% \mathrm{RH}$ and at room temperature. (Inset) A high-frequency zoom of this plot.

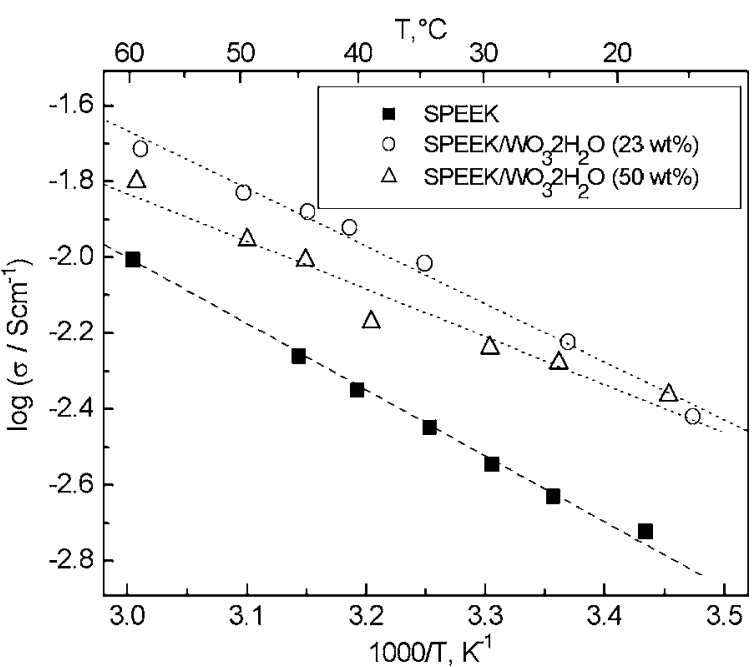

Figure 8. Arrhenius plot for as-prepared SPEEK-based membrane at $100 \%$ $\mathrm{RH}$.

served for pure SPEEK, the activation procedure did not modify their electrochemical performance, in agreement with the existence of a coordinative interaction between SPEEK sulfonic acid groups and tungsten oxide water molecules. The activation energy for the SPEEK/ $/ \mathrm{WO}_{3}$ composite membranes was found to be 0.33 and $0.28 \mathrm{eV}$ for 23 and $50 \mathrm{wt} \%$, respectively. These values are lower than the activation energy for the as-prepared SPEEK membrane $(0.37 \mathrm{eV})$. It is noteworthy, however, that the conductivity of the composite membranes was larger than that of the activated SPEEK membranes, even though the activation energy for the latter was smaller $(0.17 \mathrm{eV})$.

As already mentioned, one of the main drawbacks for membranes prepared with SPEEK with high sulfonation degree is their water solubility. Therefore, the water uptake behavior and the heat resistance of the membranes in saturated water vapor pressure conditions were investigated.

Figure 9 shows the water uptake of the three SPEEK-based membranes as a function of time. The SPEEK/WO $3(50 \mathrm{wt} \%)$ membrane showed much lower water uptake values only slightly increasing with time, whereas the pure SPEEK membrane and the composite membrane containing lower oxide concentration showed larger water uptake values, increasing with time up to 100-120\%. These findings indicate that a large oxide content drastically reduced

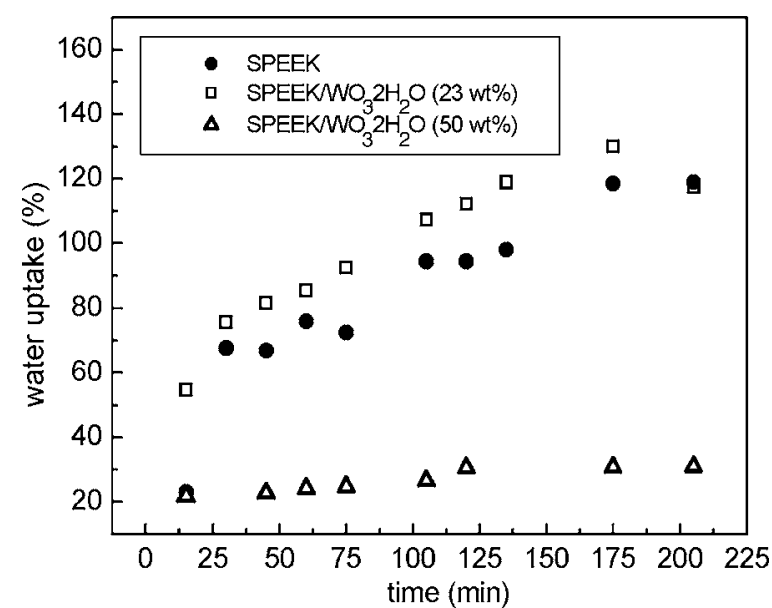

Figure 9. Water uptake values of activated SPEEK-based membranes as a function of time. 


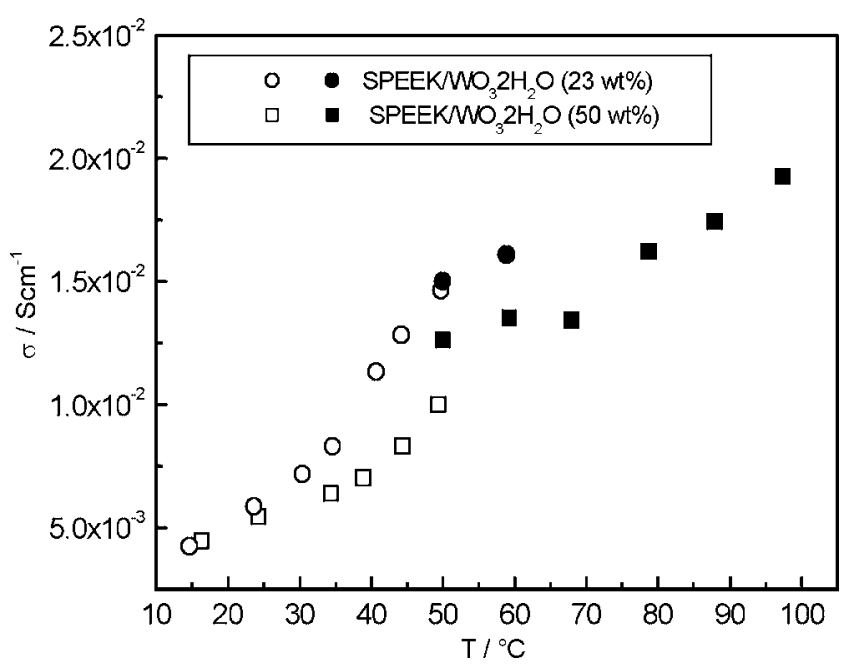

Figure 10. Proton conductivity as a function of temperature of activated SPEEK $/ \mathrm{WO}_{3} \cdot 2 \mathrm{H}_{2} \mathrm{O}$ membranes. Filled symbols: data collected after keeping the membrane at $50^{\circ} \mathrm{C}$ overnight at $100 \% \mathrm{RH}$.

the water uptake capacity of SPEEK. The control of water uptake allows balance of the need of ion-rich regions that favor proton transfer and excessive swelling, eventually leading to water solubility.

The stability of the membranes as a function of temperature in saturated water environments was investigated. Proton conductivity was measured for the three membranes with increasing temperature from room temperature up to $50^{\circ} \mathrm{C}$. Then, after keeping the membranes at $50^{\circ} \mathrm{C}$ and at $100 \% \mathrm{RH}$ overnight, the proton conductivity was measured again until dissolution of the membranes. Figure 10 shows the results for the composite SPEEK/ $\mathrm{WO}_{3}$ membranes. The pure SPEEK and the composite $\mathrm{SPEEK} / \mathrm{WO}_{3}(23 \mathrm{wt} \%)$ dissolved in the temperature range $60-70^{\circ} \mathrm{C}$, whereas the membrane with higher oxide content showed an increase in proton conductivity up to $1.9 \times 10^{-2} \mathrm{~S} \mathrm{~cm}^{-1}$ at $100^{\circ} \mathrm{C}$. After overnight exposure to saturated water vapor pressure at $50^{\circ} \mathrm{C}$, an increase in proton conductivity was measured probably because of a larger hydration of the membrane.

The composition SPEEK/ $/ \mathrm{WO}_{3} 50 \%$ resulted in a synergic merge of the electrical and physicochemical properties of the two components: the proton conductivity of the composite membrane was larger than those of the pure components; the heat resistance and solubility characteristics were improved with respect to pure SPEEK; moreover, it was possible to prepare flexible membranes with hydrated tungsten oxide, the conductivity properties of which were suitable for the foreseen application.

\section{Conclusions}

Polymer electrolyte membranes doped with inorganic proton conductors were successfully prepared. Our strategy to improve proton conductivity of both SPEEK and hydrated tungsten oxide consisted of the combination of the two materials. The composite membrane showed improved conductivity with respect to the single components, probably due to the existence of a coordinative interaction between the water molecules of tungsten oxide and the sulfonic acid $\left.\left(-\mathrm{SO}_{3} \mathrm{H}\right)\right)$ groups of SPEEK.

The presence of the oxide not only led to enhancement of the proton conductivity of the SPEEK membranes but also to the improvement of their heat resistance as well as to a decrease in their water solubility. In fact, doping a SPEEK-based material with $50 \mathrm{wt} \%$ tungsten oxide allowed preparation of a proton-conducting membrane having low swelling and high proton conductivity up to $100^{\circ} \mathrm{C}$. The combination of $\mathrm{WO}_{3} \cdot 2 \mathrm{H}_{2} \mathrm{O}$ in the polymeric matrix allowed fabrication of a membrane suitable for fuel cell applications.

\section{Acknowledgments}

This work has been financed by MIUR (FISR 2001 NUME, Development of Composite Protonic Membranes and Innovative Electrode Configurations for Polymer Electrolyte Fuel Cells Project), and by the Italian Ministry for Foreign Affairs (MAE) under the frame of the Italy-Japan Joint Laboratory on Nanostructured Materials for Environment and Energy.

Università di Roma "Tor Vergata" assisted in meeting the publication costs of this article.

\section{References}

1. C. Wieser, Fuel Cells, 4, 245 (2004).

2. G. Alberti, M. Casciola, M. Pica, T. Tarpanelli, and M. Sganappa, Fuel Cells, 5, 367 (2005).

3. S. D. Mikhailenko, S. M. J. Zaidi, and S. Kaliaguine, Catal. Today, 67, 225 (2001).

4. V. Ramani, H. R. Kunz, and J. M. Fenton, Electrochim. Acta, 50, 1181 (2005).

5. V. Baglio, A. Di Blasi, A. S. Aricò, V. Antonucci, P. L. Antonucci, C. Trakanprapai, V. Esposito, S. Licoccia, and E. Traversa, J. Electrochem. Soc., 152, A1373 (2005).

6. C. Yang, S. Srinivasan, A. S. Aricò, P. Cretì, V. Baglio, and V. Antonucci, Electrochem. Solid-State Lett., 4, 31 (2001).

7. S. M. J. Zaidi, S. D. Mikhailenko, G. P. Robertson, M. D. Guiver, and S. Kaliaguine, J. Membr. Sci., 173, 17 (2000)

8. M. L. Di Vona, D. Marani, A. D’Epifanio, E. Traversa, M. Trombetta, and S. Licoccia, Polymer, 46, 1754 (2005).

9. F. Damay and L. C. Klein, Solid State Ionics, 162-163, 261 (2003).

10. M. Hibino, H. Nakajima, T. Kudo, and N. Mizuno, Solid State Ionics, 100, 211 (1997).

11. Y. M. Li, M. Hibino, M. Miyayama, and T. Kudo, Solid State Ionics, 134, 271 (2000).

12. L. Friedman, J. Am. Chem. Soc., 81, 3834 (1959).

13. P. Barboux, R. Morineau, and J. Livage, Solid State Ionics, 27, 221 (1988).

14. M. Day, J. D. Cooney, and D. M. Wiles, J. Anal. Appl. Pyrolysis, 18, 163 (1990).

15. G. P. Robertson, S. D. Mikhailenko, K. Wang, P. Xing, M. D. Guiver, and S. Kaliaguine, J. Membr. Sci., 219, 113 (2003).

16. N. P. Berezina and E. N. Komkova, Colloid J., 65, 5 (2003).

17. M. Eikerling and A. A. Kornyshev, J. Electroanal. Chem., 502, 1 (2001). 